\title{
Cultures and Technology: An Analysis of Some of the Changes in Progress- Digital, Global and Local Culture
}

\author{
Mariella Combi
}

\begin{abstract}
The analysis presents some reflections on the changes produced by the use of digital technologies in contemporary Western societies. The scope is to understand the occurrences of the recent past, from the second half of the 1900s, and what is happening in social and individual experiences today. To devise a future, to decide how, when and what to offer in order to transmit to young people the fields of knowledge and skills that will be of use for managing their future successfully in a changing Europe. The prevailing theoretical approach is from an anthropological cultural point of view with interdisciplinary encounters. The chapter is divided into three parts: the first two are general reflections on the role of digital technologies in the past and present and focus on questions, expectations, characteristics that have interested scholars over time. The third level looks at the problematic features of people who were born after 1980, the so-called 'digital natives'.
\end{abstract}

The aim of this article is to understand the cultural changes brought about by the rapid diffusion of the new communications technology in the globalized context of the West. The main slant is from a cultural anthropological point of view, but it is inevitably also interdisciplinary due to the common ground shared with philosophy, psychology and sociology. The analysis intends to make some proposals on how to think about a European future, and how to intervene consciously in the current situation so that it keeps pace with the young, the so-called 'digital natives' (Prensky 2001). In order to do this, I begin by tracing a brief outline of the reasons why the discipline of cultural anthropology plays such an important role in the understanding of the digital revolution which today is a part of our everyday life.

M. Combi $(\bowtie)$

Sapienza Università di Roma, Piazzale Aldo Moro, 5, Rome 00185, Italy

e-mail: mariella.combi@uniroma1.it 
The new information technologies and their global diffusion have radically influenced the changes in Western society and locally. The current process of globalization has favoured and has been strengthened by the Internet which has evolved with unprecedented rapidity.

Cultural differences between groups of human beings have always been at the very core of cultural and social anthropology since it became an academic discipline: as Hunnerz (2010) says "diversity is our business". Initially the discipline was concerned with the study of non-Western, so called 'primitive' cultures, which today also have an impact on our own society. Anthropology is characterized by multiple, interconnected fields of study which make up the 'culture' of a group of human beings. This anthropological concept helps us understand what we are talking about and consists of a wide range of different realms of knowledge elaborated by all populations, and their resulting actions and behaviours. Such spheres of knowledge are organized into a cognitive structure whose content varies from group to group.

These realms of knowing are considered useful by a society to tackle everyday life, extraordinary events, and problems that give meaning to the world around them. This cultural model is learnt at birth, more or less unconsciously; people make it their own by imitation and example and it is expressed in the local language. This is not a once-and-for-all procedure but a flexible one, subject to continuous change, a life-long learning process influenced by personal experience. Culture is, therefore, essential for creating a sense of belonging and identity for every human being (Combi 2006).

Every cultural model finds its own answers to internal impulses that occur over a period of time, but above all to those produced by encounters with other cultures. The modifications, theoretical or practical, which emerge from the diversity of the fields of knowledge that characterize different societies can be influential to a greater or lesser degree. This is a case in point for changes arising from the introduction of advanced technologies, whether these are felt consciously or unconsciously in our Western culture and in other cultures. When a human group comes into contact with new elements it arranges them inside an already existing pattern, thus modifying the order of what is already known. The introduction of new technologies, for example, has led to changes which required readjustment, or new articulations, of relations between the various fields of knowledge and the daily life of both the individual and the community. Technical revolutions have also turned out to be cultural revolutions, as witnessed by the changes wrought by inventions such as the wheel, the steam engine etc., and also by the passage from an oral culture to a written one (Combi 1992).

Anthropology has the instruments to analyse cultural changes and to understand the current process of globalisation and the effects created by information technology on different societies.

The role of technology in a society shows the indissolubility of the relationships that bind technology, society and the individual as shown by this analysis which identifies the numerous cultural changes caused by the use of information technology (IT). Technology is not only the machine itself but is the whole set of 
relationships between human beings, utensils and fields of knowledge. Another important feature of anthropological theory is that it enables us to define culture as a set of communicative acts. Communication is what allows groups and individuals to represent themselves and interact with the world through norms and values.

For years now the mass media have in forecasting a future of homogenization, a levelling-out or even disappearance of cultural differences. Field research and ethnography carried out all over the world by anthropologists have maintained the contrary for decades and this has been confirmed by current trends. For example, the constant rising demand to have own cultural and linguistic features acknowledged within Nations such as the Scots in Great Britain, the Catalans in Spain, etc.

One final general observation: new technologies modify space, time, relationships and types of communication that still continue to co-exist with the other fields of knowledge inherent in a culture. The different pace of development of different societies in the world has been overwhelmed by this innovation, which has caught everyone unaware. The greater our awareness of living in a global world, the more strenuous our defence of local identity is. There is a gap between the speed at which digital technology is developing and the slow pace at which cultural models and their inherent values are changing. For example, time and space are perceived in different ways on the net and in real life, although the perception of the web is slowly influencing the perception in real life.

This push for cultural change greatly stimulated by the web, is present in all societies involved in this technological experience. Therefore, anthropology does not only seek to understand how one learns to become a member of a society, but it also seeks to understand how selection activities and human creativity modify the process of learning in order to open the mind and get to know and learn to respect the world view of others.

\section{Changes in Cultural Codes, Behaviours and Fields of Knowledge}

The following analysis is divided into the three periods of our society's time continuum past, present and future. To provide young Europeans with the necessary cognitive abilities to manage their future with greater awareness, it is essential to revise previously-held opinions and, with the benefit of hindsight, to answer questions that had no answers from the second half of the 1900s to the first decade of the twenty-first century, re-analysing the cultural changes that have occurred since then. The past that I am therefore interested in is the recent past. Many of us can hardly remember ever having lived without e-mail, computers, smart phones, all those technological devices that today seem indispensable.

Appadurai (1996) and Lévy (1997) who studied the interdependent phenomena of globalization and the computerization of society in the second half of the twentieth century, considered some aspects of the new instruments of communication problematic. Problems include: the rapidity of the transformations and rhythms 
of knowledge acquisition; the ever-increasing number of people who have access to information through computers and who produce it; the instruments of knowledge inherent in the Internet; their influence on the creation of new personal identities and interpersonal relationships. The analysis of these aspects revealed that it was not only a question of technological change in the communications system, but a transformation of knowledge in the whole of Western society. It must be remembered that the situations analysed, then and today, are different in the USA and Europe and these differences are also apparent in the time it took for IT to spread, and the impact on users and on the collective or personal identity styles in the two different linguistic and cultural contexts.

I would like to introduce some features of the new technologies that have elicited various issues in the latter half of the twentieth century. Some have become obsolete or are no longer considered interesting, others remain in the background of some of the research and our perceptions, while others still make their presence felt in the current debate.

In his work Cyberculture. Rapport au Conseil de l'Europe published in 1997, the French philosopher Pierre Lévy proposed an analysis of the situation brought about by digital technology and by the theoretical and practical implications on society. He also underlined the main problems linked to current and future changes. The salient aspects of the digital era emerged with the widespread use of personal computers in the home. Above all, Lévy showed that the new technologies were transforming global society, something that had already occurred in the past with the alphabet, the printing press, the telephone, the radio and the television.

All the questions concern the cultural implications of the new technologies, the new relationships with knowledge, the necessary changes in education and training, the conservation of linguistic varieties, problems of social exclusion, and the impact on democracy. He also offers possible lines of intervention. This awareness has prompted questions on the role of IT and the cultural and social effects that the widespread introduction of these technologies is causing and will continue to cause.

Two concepts play a key role in this analysis: cyberspace and cyberculture. The term cyberspace was first coined by William Gibson in his famous science fiction novel Neuromancer (1984) and has been successfully adopted by the collective imagination. Lévy (1997) defines it as a space, a new context opened up by the communications network produced by the global interconnection of computers. The symbol of this medium is the Internet. His notion of cyberspace includes the enormous quantity of data circulating and the people who use the Internet and foster its growth. Today cyberspace is a new realm of knowledge. Lévy uses the word cyberculture to mean the set of material and intellectual techniques, practices, attitudes, ways of thinking and values that are expressed and developed in cyberspace. Cyberculture is an enormous problem seeking solutions to constantly changing situations caused by technical developments and collective reactions. Lévy's research, in the period mentioned above, includes six features-which represent also six questions - of the phenomenon which will be described individually below.

The six questions in Lévy's work are: (1) Is there a fear of a new kind of colonization? (2) Does cyberculture encourage exclusion? (3) Is there the 
possibility of creating a direct democracy of the masses? (4) How does the transition from a passive reception of communication to an active reception change the content of the information and communication in a society? (5) Is linguistic and cultural diversity threatened in cyberspace? (6) Is cyberculture perhaps a synonym for chaos and confusion? The first of these questions is the fear of a new kind of colonization especially by the United States which is also the creator of these technologies. For example, most discussions and doubts circle around the setting up of data banks: who should insert the data, and which data are important. The worries focus on what information should be made available to everybody, what should be made available partially or not at all, and what kind of expert should be assigned to this task.

The second issue concerns a predictable rise in social inequality, with almost exclusive access by the élite. On the one hand, the answers to Lévy's questiondoes cyberculture encourage exclusion?-refer to the importance of significant economic investments in infrastructure and computers, thus denying parts of the world and groups of people access to cyberspace. While on the other hand the answers reflect the political dimension of institutional, political and cultural resistance to using forms of collective, transnational and interactive communication. Despite the optimistic forecast, due to decreasing costs and the increasing numbers of countries interconnected in different places and cultures, Lévy confirms that any new technological progress brings with it the inevitable exclusion of some. One of the objectives to aim for is the creation of that "collective intelligence" (Lévy 1999), which would increase the value of culture, foster competences, resources, local projects, collegial participation and the fight against inequality. Moreover, the danger of creating new forms of dependence linked to commercial usage and economic and political predominance with regards to the less favoured regions is to be avoided (Lévy 1997).

Access for everyone gave rise to widespread and shared expectations-which lay between the past and the present: Lévy wondered whether it was possible to create a direct democracy of the masses. The myth of equality was based on the public and social potential of communications technology in the political sphere. A virtual agorà: where the creation of a collective consciousness and pluralist discussions would give rise to a large scale direct democracy. Decisions would be taken collectively and evaluation would be tailored to the communities that participated. Wolton (1999) criticised these optimistic expectations and based his comments on the fact that without social integration and shared values there could be no direct democracy.

Lévy's approach to another issue-understanding the consequences of the transition from a passive reception of communication- TV, radio, cinema- to an active reception - the web, Internet was completely different and raised further question: How does this change the content of the information and communication in a society? First and foremost, the subject wielding the power over the information changes: as opposed to the mass media which use a system of 'from a few to many', Internet users exchange information on the basis of 'many to many'. People, no longer isolated thanks also to virtual communities, activated this new way of 
creating long-distance interpersonal links on the basis of sharing common interests. This innovation of the communication system would lead to a deeper understanding between cultures through virtual encounters with the possibility of gaining greater insight. The rapidity of communicative exchanges in time and space, made possible by the availability of the web everywhere, would lead to an understanding of the systems of symbols, values and politics, religions and philosophies of others. This was an error of judgement which did not foresee any other possible solution, such as, for example, the greater visibility of otherness and its rejection (Wolton 1999). When analysing theoretically the features of the artificial information contained in any linguistic message, it becomes clear that this new society is not at all a society of reciprocal understanding. This excessive communication is too often a symptom of self-expression rather than the desire to really step into the shoes of another person.

Another issue, summarized in Lévy's fifth question-Is linguistic and cultural diversity threatened in cyberspace? - gave rise to further debate. The use of English as the favoured language on the web is a limit for non-English speakers. On the other hand English acts as a mediator in international exchanges. Nevertheless, information had already appeared in hundreds of other languages. As successive developments show, even the technical problems linked to the use of non-Roman alphabets, and non alphabetic script have been solved. The participation of the individual determines what appears on the web, thus it is of utmost importance that people from different linguistic groups, especially those of 'minority' languages, should intervene and keep these languages alive in the virtual world.

In his last question Lévy asks whether cyberculture is perhaps a synonym for chaos and confusion. Cyberculture was considered the system of systems and, therefore, the system of chaos. He interpreted the phenomenon as a disappearance of selection, of hierarchies and of the structures of knowledge that were immutable and addressed to everybody.

The innovative feature of the web is its use as an instrument of communication among individuals which ensures that the community can teach its members what they want to know. Lévy concludes and maintains that the construction of a personal intelligence, fruit of individual effort and the necessary time to learn it, is inevitable. It is not difficult to see even today that the image of the web is chaotic. The setting up of netiquette marks a first initiative to control the lack of discipline on the Internet. Netiquette is the guide to the Internet, which introduces norms that govern issues of legality and good behaviour on the web.

This brief discussion of Lévy's six questions and his future proposals concerning the changes in the cultures only partially reflects the research taking place at the time but is certainly enlightening for today. It is clear that cultural models in the Western world have undergone great changes. Every society elaborates codes of communication that are considered essential for the transmission of knowledge and interpersonal and intercultural encounters - just think of oral, written, non verbal and visual communication. Communication is a kind of reflection of society; in fact every language manages to express all the culture devised by a group of people. Today more than ever, these technological changes must make us aware of the 
importance of existing cultural diversity in the European context, its richness and the history that links different countries. It is easier to focus on what individuals and cultures have in common rather than deal with the complexity of their differences.

Although new technologies appear to favour proximity among human beings, in fact the opposite effect is true and much more deceptive. This is why it is so important to be aware of the fact that the differences in the content of knowledge and the actions springing from it, exist beyond the shared use of the communication codes used on the web. This is because behind the software and the hardware there are human beings who decide what a programme should or should not do. Their choices are guided by their personal interests and aims, and their own cultural and emotional experiences. This means that surfing the web is not a neutral or objective experience, but is the result of decisions made by someone who knows how to exploit the expectations of the moment, who means to obtain some economic profit from this activity and who maintains control of the information.

Thus digital technology does not eliminate the inevitable acquisition of a cultural model which gives you the perception of belonging to a society or a real community. It accompanies the latter and modifies it by transforming knowledge, interpersonal relationships and behaviour which apparently connect young people today. Digital technologies are similar round the world but fortunately encounter a diversified cognitive world in the different localities. The local culture acquires the new technologies, re-works them to make them acceptable to the existing culture in that community and sends them back to the global level in a continuous exchange of intercultural influences and in constant transformation. A little like the wearing of jeans: everybody, 'primitive people' and rich Westerners alike, wear them, but the individual wearing them expresses values, concepts, ethics, norms, religious beliefs and images learnt from his own group which differ greatly from all other groups.

The chapter continues with the discussion of cultural changes that have occurred to date because some categories today have become more evident or have changed: they are influencing people's perception of the world stimulated by the use of the web and the Internet. Categories involving more personal attitudes to a 'digital native' will be dealt with in the final part concerning proposal for the future.

The following categories - space-time; values; veracity; transparency; creativity and imagination-involve more general cultural context and will be dealt with below. The space-time category has undergone great changes. Space plays a significant role in all societies, as human beings, always and everywhere, modify the natural environment and transform it into a local cultural environment. Locality reflects the creative solutions that the inhabitants of a particular space have adopted to deal with problems of survival. This process has some implications of power as, for example, in the relationship between the centre and the periphery of the world, of a nation or of a city. Digital technology has made it possible to re-position the two concepts: peripheral places can now influence the centre, make the world aware of their existence. There are two active processes concerning space on the web: deterritorialization and decontextualization. The former implies the knocking down of borders, nomadic movement, going beyond the sense of place and living anywhere in cyberspace. This reminds us also that every local context is really a 
temporary form of passage that embraces linguistic experiences and life-styles that vary in the course of time. Decontextualization, the absence or lack of importance of reference points of communication, goes hand in hand with deterritorialization.

In a situation of communication the cultural and temporal context cannot be disregarded because it influences the meaning and enables a correct interpretation of the information. On a general level, even the construction of a local identity and the recognition of otherness needs to be contextualized, to be considered consciously. When space loses its physical nature and changes into a conceptual space it becomes ubiquitous, thanks to new technological devices, and the instantaneous links which cancel the perception of spatial distance. Digital technology connects any point in the world with another and at the same time information can be retrieved from any point in the world in real time so that the traditional spatialtemporal parameters are made obsolete by the global dimension and instant nature of communication on the web.

Traditionally the perception of time is shared by all members of a real community but is at the same time linked to subjective experience. Today, the most significant features of the perception and organization of time in Western online and offline contemporaneousness are: the perception of accelerated time and the present lived as if it were a continuous moment which cancels the past and the future; people surf in a present without end. There are no intervals of solitude, silence, or isolation dedicated to reflection and imagination and no opportunity to evaluate the seriousness of a problem and create a hierarchy of priorities. Contrary to what was maintained at the beginning of this technological adventure (you will have more free time ...) everyday life shows that all of us are always in a hurry, that there is no time.

Also the role played by values in real life, in the virtual sphere and in the education for a future for everyone is changing. As shown by Gardner (2012), a psychologist who works with minds and the cognitive abilities required for the future, in his book Truth, Beauty, and Goodness Reframed. Educating for the Virtues in the Twenty-first Century. We must re-educate young people to the values. At this point, we must deal with Lévy's (1997) last question — whether cyberculture breaks with the values of European modernity? This gives the philosopher the opportunity to reply that cyberculture pursues and realizes the progressive ideals of the eighteenth century, which sustained the emancipation of human beings, participation in debate and discussion groups, exchange of information and believed in three values: liberty, equality and fraternity. Despite this continuity, Lévy highlights his expectations of a radical renewal of political and social thought in Europe, a renewal which has not taken place yet.

Another important change in attitude to online communication concern the veracity of information. Internet users do not set great store by truth; do not check or cite the source of information. The very fact that the information appears on the web automatically seems to confer authority on the information and the user can take possession of it with impunity. This lack of discernment, which should differentiate between credible, official or institutional sources and sources such as paedophiles, terrorists, criminals and manipulators, is dangerous. The initial 
conviction that the instant distribution of news in all parts of the world would guarantee transparency has faded. Nevertheless, nobody doubts that the goal of transparency and veracity will be reached in the next decades. The main problem is: how will it be achieved? According to Wolton (1999), transparency is impossible as social relationships are never transparent and technical bureaucracy must be added to human bureaucracy, both with their own hierarchies.

Two further categories, creativity and imagination, have undergone great changes on the web. The perception of an image, an element of imagination, is based on the personal history and values of the individual and the new technologies offer an incredible number of incentives and new instruments to give vent to one's imagination and creativity, especially the latest app. However, there are limits to this process set by the specific structure of the application and the codes invented by the designer of the product.

In conclusion: the general characteristics of essential cultural change is being able to do things that were not possible before: the instant circulation of information; the uninterrupted 24-h link with people or software all over the world; the personal presentation of yourself and your own creativity and imagination; the knocking down of real borders; the transnational nature of the circulation of ideas and instruments ever smaller, more powerful and lighter laptops, smart phones, IPods, IPads, tablets, wearable technology etc.-no longer only 'many to many' communication but also 'always-on'. Today communication via the computer occurs in real time, is reciprocal, interactive and non-stop.

\section{Some Considerations Concerning 'Digital Natives'}

The term 'digital natives' (Prensky 2001) is applied to people born after 1980-1990 when social digital technologies came online. They are young people who have access to networked digital technologies. The use of those technologies have also changed the way they think and process information. An in-depth analysis of the 'digital native' makes it possible to link up with things said at the beginning.

One of the main tasks that awaits anthropological cultural research is that of reflecting on the cultural changes that have been produced by the new technological changes in our society. And make young people aware of the limits of technology into which they place a great part of their lives. Such changes need an educational or, in a broader sense, formative model, which acknowledges the new ways of learning and communicating of the young of the 'app generation' and the social networks. The features of the new media-speed, accessibility, easy acquisition, transfer and transformation of information, possible anonymity, and multiple identity - cannot be ignored especially due to their problematic aspects mentioned above.

This chapter targets these young people who are the focus of European research projects which provide us with a general profile of this generation and cannot ignore the changes in the wider social context discussed above and the positive online experience. Some of the questionable characteristics of a 'digital native' are: 
identity problems; narcissism and self-promotion; difficult local/global relation; growing individualism; reluctance to accept responsibility and risk; distorted perception of time. Above all we cannot ignore the great transformation of the web which from information supplier, with web 2.0 has become a social space, highlighting the constant search for social encounters, and contacts like 'anytime anywhere', 'many to many', 'peer to peer' which favour encounters, friendships and virtual and real comparisons.

The research undertaken by Gardner and Davis (2013) offers us an interesting viewpoint on the learning process of young people today and their limits. By analysing the consequences of the general and invasive use of app in everyday life, what does living in a 'world of apps' really mean for the future of our species and our planet? the authors ask themselves. Apps are procedures that allow the user to obtain a result rapidly and pleasantly. However, they have effects that may turn out to be negative, because the invasion of a person's everyday life by apps favours the construction of a worldview based on their codes. They are 'shortcuts' that speed up interaction, simplify them and make them less risky.

From a personal point of view, apps embrace a set of interests, habits and relationships that characterize an individual: it is personal identity revealed to the outside. Their general use influences aspects of a personality which tends to take on the form of a "tailor-made self" (Gardner and Davis 2014) a positive and directed at self-promotion, which is desirable but distracts the attention from the inner self, the deepest feelings and personal projects. Some specific traits linked to self promotion online are encouraged by the presumed anonymity of the web. For example, you do not show how you really live but only how you appear to live, even if the image is not far from reality. Young people do not really consider their online and offline identities as being very different just as the private and public spheres are not really considered separate.

Another new aspect involves the concept of interculturality: the young are aware of a global outlook but often lack a deeper understanding due to a poor cultural background and, the authors add, they speak globally but act locally. The apps provide them with the opportunity to access experiences outside everyday life, but it is not known how much the young really benefit from them even if the acceptance of otherness has increased. This is an aspect of the "respectful mind" (Gardner 2006) which implies an open attitude towards knowledge and an acceptance of people and things that are culturally different.

The new communication technologies also play a role in giving young people a sense of security as they avoid many risks of real life, such as finding their way in unknown places or dealing face to face with the unexpected reactions of a person. Once again the importance of remaining in constant contact with reality and direct relationships emerges as a reference point for experiencing significant relationships thus going against the trend of increasing isolation and decreasing empathy. Many young Europeans share these characteristics described above and are preparing for a future with many uncertainties. 


\section{$3 \quad$ Looking at the Future}

As a conclusion to the above considerations it would be useful to ask ourselves what proposals we can make to prepare young people for the future. Technology influences communication because it offers new elements in the creation of imaginary subjects and worlds. They tend to integrate subvert and transform other contextual forms of learning (Appadurai 2013). That is why thinking about the future means selecting and providing knowledge which will be of use to them in the years to come. To this end I would like to highlight some cultural features which, in my opinion, play an important role in the acquisition of awareness, competences and capabilities to tackle the future. These features, which intend to provide young Europeans with the necessary instruments, should also feature as relevant aspects in any research on young people in Europe. Amongst others these are: acquiring the awareness of one's local and European identity; learning to think in an intercultural and interdisciplinary manner; acquiring the ability to synthesize; overcome the perception of time as one continuous moment.

The proposal relevant to the relationship between local and global culture focuses on the fact that learning about the cultures of other European countries (and not only) helps one to think about one's own culture. The young use technology to communicate but know little or nothing about the countries that youngsters of their own age live in and are full of stereotypes and prejudices. There is no conscious identity without the encounter of otherness, anthropologists say, especially if one focuses on beliefs, traditions, language, myths, rites, tastes, which on first impact are different from one's own. Getting to know others, reflecting and thinking critically about oneself makes one aware that every person is the expression of a cultural model with its own features which only the encounter with otherness brings into evidence. Student exchange programs, for example, provides a practical situation for experiencing otherness, which makes young people aware of the local dimension of their own culture which is a specific expression of knowledge. In fact, we tend to consider our beliefs, behaviour, habits, physical and emotional expressions, which we share with other members of our society, as 'natural'. They are really the expression of that particular culture which we belong to and differ from those of other cultures. Ethnocentrism, which considers one's own culture as superior, is common to all groups of human beings. This mental attitude is at the root of many incomprehensions, also at the communication level in intercultural meetings and makes negotiation difficult if not impossible.

This means that young people must learn to give priority to an intercultural approach fostered by the discovery and the comparison of the features of two or more cultures. This kind of approach must go hand in hand with an interdisciplinary approach. The latter is not simply meant as bringing different realms of knowledge together but also as a meeting place for different theories and methods to create a new point of view, a new approach to problems not achievable through single disciplines. These two approaches require one to select a particular subject matter (anthropology, literature, history, geography, art, the history of religions, etc.) best based on personal interests. In this way it is possible to carve out a mental path, 
which guides the forays into the Internet to find what one is looking for without getting lost and constantly returning to the starting point, and consequently stops a person from feeling overwhelmed by the cognitive incongruence of the situation, the fragmentary and superficial nature that is characteristic of many people who surf the web. I am referring to the "disciplined mind", one of the five minds Gardner (2006) considers essential for the future, which requires in-depth knowledge of the theories, methods and paradigms of a discipline. The other four minds Gardner specifies are: the "synthesizing, creating, respectful (already mentioned) and ethical" briefly summarized below.

The skill of synthesis, the synthesizing mind is fundamental in overcoming the superficial and fragmentary nature of an unconscious personal technological learning process, which favours non-knowledge; without taking anything away from the positive effects of the new technologies and the web 2.0 world, as for example, a greater acceptance of diversity (ethnic, sexual, cultural). Furthermore, synthesis requires greater detail and slow memorization which implies the perception of the difference between quality and the quantity of the data. The latter are characteristics, for example, of multitasking, when people work on various communication fronts at the same time. Once again technology favours the quantity and speed of the passage between different technological supports, but the information that comes into play is superficial to the detriment of quality and analytical correctness.

One important effect of the total immersion in the web is to upset one's perception of time which is one of the revolutionary changes of information technology. Art and literature, for example, are fitness to the existing relationship between time and contemporaneity. In Augé's analysis (2015) the latter in particular, is seen as the taking on of the past and the future of the different generations. Behavioural and social sciences, art and literature today have to rise to the same challenge of a world which perceives time as accelerated and sees the present as one continuous, never-ending moment. The trend is to live in one endless moment, an immediate present that cancels the dimensions of the past and thus also precludes the future.

According to Gardner (2006) the ethical and creating minds complete the wealth of intelligence he considers fundamental for the future. They are fundamental as they include the dimension of values. The ethical mind allows a person to reflect on the principal features of the role they play at any particular moment of their life. This is essential as it means that they can recognise the responsibilities inherent in this role and the consequent morally correct behaviour. The creating mind is the most developed in the technological world with particular and endless references to the artistic-literary environment.

Any research attempting to understand a society and foresee its changes in the future must take place in a cultural anthropological context as indicated at the beginning of this chapter. It provides a flexible network of interconnections between the different realms of knowledge that characterize all groups of human beings. That is why it cannot be ignored when analysing the great cultural and technological changes involving all human beings all over the world. Cultural 
anthropology provides the methodology for a comparison between different European cultures (and not only) and to analyse cultural changes, wherever these occur. It also provides the opportunity to draw people closer to 'indigenous' cultural products, especially, all artistic expressions. They favour comparisons and the crossing of the borders of local cultures, they make it possible to participate in global creativity starting from taking pride in one's own origin. New technologies, if used properly can help this process and open one's mind to the meeting with expressions of knowledge conceived by other human beings.

Open Access This chapter is distributed under the terms of the Creative Commons AttributionNoncommercial 2.5 License (http://creativecommons.org/licenses/by-nc/2.5/) which permits any noncommercial use, distribution, and reproduction in any medium, provided the original author(s) and source are credited.

The images or other third party material in this chapter are included in the work's Creative Commons license, unless indicated otherwise in the credit line; if such material is not included in the work's Creative Commons license and the respective action is not permitted by statutory regulation, users will need to obtain permission from the license holder to duplicate, adapt or reproduce the material.

\section{References}

Appadurai, A. (1996). Modernity at large: Cultural dimensions of globalization. Minneapolis: University of Minnesota Press.

Appadurai, A. (2013). The future as cultural fact. Essays on the global condition. New York: Verso Book.

Augé, M. (2015). The future. New York: Verso Book.

Combi, M. (1992). The imagery, the computer, artificial intelligence: A cultural anthropological approach. AI \& Society: The Journal of Human-Centred Systems and Machine Intelligence, 6 (1), 41-49. London: Springer.

Combi, M. (2006). The construction of flexible identities and negotiation of meanings on the Internet. In M. Negrotti (Ed.), Yearbook of the artificial. Kyosei, culture and sustainable technology (pp. 10-16). New York: Peter Lang.

Gardner, H. (2006). Five minds for the future. Boston: Harvard Business School Press.

Gardner, H. (2012). Truth, beauty, and goodness reframed. New York: Basic Books.

Gardner, H., \& Davis, K. (2014). The APP generation. New Haven, CT: Yale University Press.

Gibson, W. (1984). Neuromancer. New York: Ace Books.

Hunnerz, U. (2010). Anthropology's world: Life in a twenty-first-century discipline. London: Pluto press.

Lévy, P. (1997). Cyberculture. Rapport au Conseil de l'Europe. Paris: Éditions Odile Jacob.

Lévy, P. (1999). Collective intelligence: Mankind's emerging world in cyberspace. New York: Basic Books.

Prensky, M. (2001, October). Digital natives, digital immigrants. Horizon, 9(5), 1-6.

Wolton, D. (1999). Internet et après? Une théorie critique des nouveaux medias. Paris: Flammarion. 